\title{
The BRAIN Principle: Managing Wounds After Application of Bioengineered Alternative Tissues to Maximize Incorporation and Wound Healing
}

\author{
by Jonathan Moore, DPM, MS ${ }^{1 凶}$
}

The Foot \& Ankle Journal 1 (5): 3

The efficacy of bioengineered alternative tissue (BAT) for lower extremity ulcers (diabetic and nondiabetic) is well described in the literature. What is not present in the literature is a concise description of how to manage these fragile biological tissues after application. This paper introduces the BRAIN principle for adjuvant management of wounds after application of bioengineered alternative tissues. Based on the experience of the author, utilizing the principles found in the BRAIN protocol have not only demonstrated improved BAT incorporation rates, it also increased the rate of wound closure.

Key words: Diabetic wounds, bioengineered alternative tissues, wound healing

This is an Open Access article distributed under the terms of the Creative Commons Attribution License. It permits unrestricted use, distribution, and reproduction in any medium, provided the original work is properly cited. @The Foot \& Ankle Journal (www.faoj.org)

Bioengineered Alternative Tissues (BAT's) have revolutionized the science of wound healing. These new technologies offer the wound care specialist an important tool in the battle to prevent nearly 90,000 amputations that occur annually among diabetic patients. ${ }^{7}$ However, this technology is of little value when not used as a part of a comprehensive approach to wound healing. This includes assessing nutrition, metabolic status, vascular status, off loading options, and choosing the right wound healing product.
As new bioengeenered alternative tissue products enter the market it is important to consider patient expectations and treat the patient with the best product available for their specific wound. While there are procedures described for many of the better-known BAT's on the market, they differ in many respects. The table in the study demonstrates the differing protocols for "aftercare" following applications of these products. (Table 1)

Choosing the right BAT along with the appropriate topical wound care agent is critical not only to improve healing times, but to also lower costs.

\footnotetext{
Address correspondence to: Jonathan Moore, DPM, MS Cumberland Foot \& Ankle Center. 117 Tradepark Drive, Somerset, KY 42503

${ }^{1}$ Cumberland Foot \& Ankle Center. 117 Tradepark Drive, Somerset, KY 42503.
} 


\begin{tabular}{|c|c|c|c|c|c|c|}
\hline & $\begin{array}{c}\text { GraftJacket }{ }^{\circledR} \\
\text { (Wright } \\
\text { Medical } \\
\text { Technology, } \\
\text { Inc., } \\
\text { Arlington, } \\
\text { TX) }\end{array}$ & $\begin{array}{c}\text { Oasis }{ }^{\circledR} \\
\text { Wound } \\
\text { Matrix } \\
\text { (Healthpoint, } \\
\text { Ltd., Fort } \\
\text { Worth, TX) }\end{array}$ & $\begin{array}{c}\text { GammaGraft }{ }^{\circledR} \\
\text { (Promethean } \\
\text { LifeSciences, } \\
\text { Inc., } \\
\text { Pittsburgh, } \\
\text { PA) }\end{array}$ & $\begin{array}{c}\text { Apligraf }{ }^{\circledR} \\
\text { (Organogenesis, } \\
\text { Inc., Canton, } \\
\text { MA) }\end{array}$ & $\begin{array}{c}\text { Integra }{ }^{\circledR} \\
\text { (Integra } \\
\text { LifeSciences } \\
\text { Corp., } \\
\text { Plainsboro, } \\
\text { NJ) }\end{array}$ & $\begin{array}{c}\text { Dermagraft@ } \\
\text { (Advanced } \\
\text { BioHealing, } \\
\text { Inc., La } \\
\text { Jolla, CA) }\end{array}$ \\
\hline $\begin{array}{l}\text { Frequency of } \\
\text { dressing } \\
\text { changes } \\
\end{array}$ & $3-5$ days & $1-3$ days & Once & $3-5$ days & 3 days & 3 days \\
\hline $\begin{array}{l}\text { Recommended } \\
\text { primary } \\
\text { dressing }\end{array}$ & $\begin{array}{c}\text { Gauze } \\
\text { saturated with } \\
\text { sterile mineral } \\
\text { oil } \\
\end{array}$ & Nonadherent & Nonadherent & Nonadherent & Nonadherent & Nonadherent \\
\hline $\begin{array}{l}\text { Recommended } \\
\text { secondary } \\
\text { dressing } \\
\end{array}$ & Gauze & $\begin{array}{l}\text { Hydrogel or } \\
\text { absorptive } \\
\text { dressing } \\
\end{array}$ & Gauze & Foam or gauze & $\begin{array}{l}\text { Foam or } \\
\text { gauze }\end{array}$ & Gauze \\
\hline $\begin{array}{l}\text { Monitor for } \\
\text { signs/symptoms } \\
\text { of infection }\end{array}$ & Yes & Yes & Yes & Yes & Yes & Yes \\
\hline $\begin{array}{l}\text { Manage } \\
\text { exudate and } \\
\text { maintain moist } \\
\text { wound } \\
\text { environment }\end{array}$ & Yes & Yes & Keep dry & Yes & Yes & Yes \\
\hline
\end{tabular}

Table 1 Application and Aftercare Instructions to Providers from the Manufacturer.

It has been estimated that 15 to 20 percent of individuals with diabetes will suffer from lower extremity ulceration during their lifetime. ${ }^{8}$ Furthermore, half of the diabetic patients who have had a leg amputated will loose the other leg in three to five years. In 1997 it was estimated that total costs for both direct and indirect health care for the persons with diabetes was $\$ 98$ billion. Of this total, direct medical costs including hospitalization, medical care, and dressing supplies, accounts for $\$ 44.1$ billion. ${ }^{9} \quad$ What is more startling is the annual $\$ 5$ billion dollar price tag estimated for the cost of dressings for these conditions. With the increased cost of wound care, the wound care specialist should consider using protocols that not only maximize wound healing, but also minimize the risk of BAT failure by providing the best tools to maintain the optimum environment for the wound.
While it is not the purpose of this paper to review every type of BAT on the market, it is vital to understand the characteristics of these products in order to understand how they work and how they should be adjunctively managed after application.

For purposes of defining terms, BAT's are products that have been produced artificially or modified in some way that alters the biology and its interaction with the wound bed with the goal of creating an optimal environment to stimulate healing.

These tissues include both allograft, xenografts and manufactured/engineered biologic products like Apligraf ${ }^{\circledR}$ (Organogenesis, Inc., Canton, MA). The purpose of these tissues has been well established in the medical literature. However, the primary goal in using a BAT is to stimulate granulation of a chronic wound and augment the wound's intrinsic healing pathway, thus creating a bridge to epithelialization of the wound. 


\section{T I M E}

\begin{tabular}{|c|l|}
\hline $\mathbf{T}$ & Tissue management \\
\hline $\mathbf{I}$ & Inflammation and Infection control \\
\hline $\mathbf{M}$ & Moisture balance \\
\hline $\mathbf{E}$ & Epithelial advancement \\
\hline
\end{tabular}

Table 2 International Wound Bed Preparation Advisory Board - TIME principles.

The literature has well described the process of preparing the wound bed for application of a BAT. The TIME acronym as proposed by the International Wound Bed Preparation Advisory Board provides an exceptional framework for the physician to improve the opportunity for wounds to heal. The TIME principle in essence describes an approach to remove the barriers to the woundhealing process in order to optimize wound repair and healing. Removal of these barriers will not only help to establish a well-vascularized wound bed, but they will also be vital for the incorporation and success of a BAT. (Table 2). ${ }^{10}$

While the principles of TIME described above remains important a new set of principles are needed to assure the BAT has the best chance of incorporation and healing the wound in a timely manner.

Thus, the following acronym called BRAIN is proposed. (Table 3)

\section{The BRAIN Principle}

\section{B (Bioburden)}

Despite having properly prepared the wound bed before application of the bioengineered tissue through debridement, among other modalities, maintenance of the bioburden after BAT application remains important. Non-cytotoxic antimicrobials should be considered to prevent colonization after application of bioengineered tissues.

\section{B R A I N}

\begin{tabular}{|c|l|}
\hline $\mathbf{B}$ & Bioburden \\
\hline $\mathbf{R}$ & Reduction of pressure and shear force \\
\hline $\mathbf{A}$ & $\begin{array}{l}\text { Adapting to the moisture needs of the } \\
\text { wound and the bioengineered tissue }\end{array}$ \\
\hline $\mathbf{I}$ & Incorporation and Identification \\
\hline $\mathbf{N}$ & Nonadherent dressing \\
\hline
\end{tabular}

Table 3 The BRAIN principles to maximize BAT incorporation and wound healing.

Proper assessment to the needs of the wound is vital after application of the BAT in order to reduce the chances of infection. In the event of a clinical infection of a chronic wound, aggressive treatment is recommended to prevent limb loss. The following are recommendations that should be considered after application of a BAT for the prevention of infection:

1. Sharp debridement is the fundamental component in preparing the chronic wound for the BAT, whether it is an allograft or a bioengineered skin equivalent, like Apligraf ${ }^{\circledR}$. Sharp debridement too early after application of the BAT may result in destruction of the bioengineered tissue or disruption of the materials the BAT was able to establish in the wound bed. Debridement post BAT application should only be considered if there is necrotic or infected tissue present.

2. Application of a topical antimicrobial agent for use on the wound bed prior to application of the BAT (at least 2 weeks prior), in order to decrease bacterial colonization, should be considered for both cellular engineered tissues and allografts. Use of a silver containing antimicrobial agent, as a part of wound bed preparation should not be a problem, as the silver will be inactivated by wound fluid among other wound components. Application of a topical antimicrobial agent post application of a BAT remains controversial. 
Living skin equivalents like Apligraf ${ }^{\circledR}$ should not be used in conjunction with any silver-based topical antimicrobial agent as these can be, at certain levels, cytotoxic to keratinocytes and fibroblasts. ${ }^{11}$ While there is debate about other types of topical agents used on or with a living skin equivalent like Apligraf ${ }^{\mathbb{B}}$, I have used Bacitracin ointment as well as AmeriGel ${ }^{\circledR}$

Hydrogel Saturated Gauze Dressing (Amerx Health Care Corporation, Clearwater, FL) pre and post application of Apligraf ${ }^{\circledR}$ pose no adverse clinical effects. Agents that are known to be cytotoxic to living skin equivalents include: Dakin's solution, Mafenide Acetate, Scarlet Red Dressing, Tincoban, Zinc Sulfate, Povidoneiodine solution, Polymyxin/Nystatin and Chlorhexidine.

3. Care must be taken to control swelling and edema with careful compression over the BAT site taking care not to compromise circulation. Edema can significantly compromise wound healing and incorporation of the BAT.

4. Systemic antibiotics should be considered in the presence of malodorous drainage, friable necrotic tissue, increased levels of wound exudate, increasing pain, surrounding cellulitis, crepitus, necrosis and lymphadenopathy. Fever, chills, malaise, leukocytosis, and an elevated erythrocyte sedimentation rate are also common systemic manifestations of wound infection. Superficial contaminants are not always representative of the wound status, as healing wounds will have some contamination. Macerated tissue culture or curettage is a reliable way to determine the etiology of a serious wound infection. Infected wounds will typically respond to aggressive debridement with appropriate systemic antibiotic therapy. Indiscriminate use of oral antibiotics will not decrease infection rates, but can result in resistance. Gram-negative bacterial infections can be severe and need to be treated aggressively. ${ }^{12}$

\section{$\mathbf{R}$ (Reduction of pressure and shear force)}

In order for incorporation of the BAT to take place in the chronic wound, excess pressure, motion and shearing must be eliminated. Unless the bioengineered tissue maintains adherence to the wound bed with proper pressure redistribution, BAT incorporation will fail. The medical literature is replete with articles that stress the importance of offloading during wound healing. ${ }^{13}$

Although there are many devices on the market that can be employed to remove plantar pressure $\left\{\right.$ Bledsoe ${ }^{\circledR}$ Walker (Bledsoe Brace Systems, Grand Prairie, TX), DH Walker ${ }^{\circledR}$ (Royce Medical, Inc., Camarillo, CA) or total contact casting\}, care must further be taken when applying the BAT to the wound site.

Although most BAT manufacturers recommend some type of anchoring of the bioengineered tissue to the wound (i.e. sutures, staples, etc.), specific protocols are lacking. The following are recommendations to consider for the development of your protocols:

1. Determine the best and the most secure application method based upon the quality of the tissues and the location of the BAT. Plantar pressures will deteriorate the BAT unless properly offloaded and secured. With dorsal wounds, anything creating pressure or shear over the site will also result in the failure of the BAT.

2. Although suturing the BAT to the wound bed is ideal, in cases of severe tissue atrophy or poor skin perfusion, Steri-Strips ${ }^{\mathrm{TM}}$ (3M, St Paul, MN) should be considered to prevent worsening of the wound site.

3. If sutures or staples are employed, be careful to make sure the bioengineered tissue has been adequately fenestrated in order to prevent hematoma or seroma formation under the BAT. 
4. Plantar ulcers MUST be offloaded in order for the BAT to incorporate. Ideally, no pressure should be applied to the wound site, if possible. Surgical shoes with a Velcro ${ }^{\circledR}$ (Velcro Industries B.V., Manchester, NH) latch should be considered for dorsal foot wounds in order to prevent rubbing or shearing forces.

5. Regular shoes, flip-flops or any like footwear are contraindicated after application of any BAT and should NOT be employed.

\section{A (Adapting to the moisture needs of the wound and the bioengineered tissue.)}

Any BAT must stay hydrated in order to achieve wound incorporation. Early desiccation of the wound bed and the surrounding tissues will ultimately lead to BAT failure and subsequent slower healing times. The concept of keeping wounds moist in order to accelerate wound healing has been known now for over 50 years. ${ }^{14,15}$ Contrary to conventional wisdom, keeping the wound site and the BAT moist does not increase the risk of infection. In fact, a moist wound environment has been shown to improve wound healing by up to $50 \%$ compared with exposure to air. $^{16}$

Many factors will determine the amount of wound fluid present in the wound bed. Venous ulcers, for instance, are more likely to produce more moisture than an ulcer on the top of the foot. Close assessment of the moisture balance in the wound is critical for the success of the BAT. Fluid from chronic wounds will block cellular proliferation and angiogenesis, and will ultimately impair wound healing through the build up of excessive amounts of matrix metalloproteinases (MMPs) that break down critical matrix proteins. ${ }^{17}$

The dressing choice after the application of the BAT to the wound site is vital in order to properly adapt to the moisture needs of the wound. Here are some considerations:
1. Upon review of many bioengineered tissue dressing protocols, as provided by the manufacturers of the top BAT's on the market, regular gauze is recommended as a secondary dressing in nearly all. (Table 1) Although the purpose of the gauze is understood to provide some level of absorption of drainage from the wound, this concept is not ideal for several reasons. No matter how much hydrogel or mineral oil you use under a regular piece of dry gauze, most of this will be absorbed by the gauze and thus provide minimal moisture to the wound bed over time.

Regular gauze alone, even with a nonadherent dressing of some sort, cannot provide consistent and long lasting moisture to the wound site. Hydrogels and hydrogel impregnated gauzes formulated with substrates allowing for longer and controlled moisture balance reduces the incidence of adhesion to the BAT and wound site. Saline or glycerin-based hydrogels or hydrogel impregnated gauzes frequently result in premature desiccation and should be avoided.

2. In those cases where excessive wound fluid is evident, more frequent dressing changes is recommended.

3. In cases of severe exudate and draining from the wound site, the presence of infection needs to be addressed and antibiotics should be prescribed.

4. The ideal wound dressing will remove the excess amounts of wound exudates while retaining a moist environment that accelerates wound healing.

Keep in mind that healing wounds are always characterized by high mitogenic activity, low inflammatory cytokines (less chronic wound fluid), low proteases, mitotically competent cells and a moist environment. 


\section{I ( Incorporation and Identification)}

Successful incorporation of a BAT hinges upon the molecular environment of the wound. Incorporation of the acellular BAT into the wound bed through a collagen matrix allows for the recruitment of cells into the wound and facilitates the induction and expression of growth factors and cytokines necessary for wound healing. The balance between collagen degradation and synthesis can be disrupted by disease states like diabetes. This can result in defective collagen metabolism and disrupted wound healing.

In contrast, cellular BAT's are designed to accelerate tissue regeneration by stimulating the recipient's own wound bed derived skin cells. ${ }^{18,19}$ Some authors have called the BAT an interactive "drug" delivery system by the transfer of MMPs and cytokines from the BAT into the wound. ${ }^{20}$ Acellular BAT's work by effectively providing a cover for the wound that prohibits desiccation and fluid loss within the wound, thus decreasing the bacterial burden and promoting angiogenesis and allowing vascular ingrowth into the dermal layer of the allograft.

Identification and correction of factors that can cause tissue damage is essential after application of a BAT. Keep in mind that cellular bioengineered alternative tissues work by biochemically balancing the wound environment to promote tissue regeneration. This provides the "primordial soup" of mediators and growth factors. $^{21}$

Among the many things that can impair wound healing (systemic steroids, non-steroidal antiinflammatories, immunosuppressive drugs), several other factors must be recognized:

1. Localized edema from venous insufficiency or lymphedema must be addressed before and after application of a BAT. Compression therapy or a referral to a certified lymphedema specialist should be considered.
2. Low albumin can have a significant impact on wound healing. A deficiency in serum albumin, which accounts for more than $50 \%$ of total serum proteins, impairs the inflammatory and proliferative stages of wound healing while also decreasing wound perfusion. $^{22}$ A dietary or nutritional consult should be ordered to maximize the body's own potential to heal.

3. Autonomic Neuropathy resulting in over drying of the wound and surrounding tissues will impair wound healing in many ways. Desiccation within the wound site will slow epithelial cell migration and thus prevent the incorporation of the BAT.

4. Infection within the wound site can present many challenges to the incorporation of the BAT. Infection must be treated without delay through either debridement, antibiotics, wound cleansing, or wound disinfection.

5. Hyperglycemia must be addressed in order to have successful incorporation of the BAT. Although the wound care specialist may not be able to directly influence this factor, all efforts need to be made to communicate with the primary care provider and patient to gain better control the patient's blood sugar. Behavior modification regarding diet and exercise is always an immense challenge in the diabetic population. ${ }^{23}$

\section{N ( Nonadherent Dressing)}

It has been said that the choice of the wound dressing at one stage of the wound may well influence subsequent events in the later phases of healing. ${ }^{24}$ In reviewing the protocols set forth by most BAT manufacturers, the one common denominator among all of them is the recommendation of a "nonadherent dressing" as the primary dressing to be used over the bioengineered tissue. (Table 1) 
While the goal of the nonadherent dressing is to prevent trauma or adhesion of the secondary dressing to the BAT (or underlying tissues), few of these products possess the characteristics ideal for covering a bioengineered tissue. While it is possible for several different types of dressings to be employed over the BAT at once (i.e. petrolatum impregnated gauze, antibiotic cream, hydrogel, mineral oil followed by an absorptive 4" $\mathrm{X} 4$ " pad or a foam), this is impractical and expensive.

\section{Ideal Characteristics of the Primary Dressing for Coverage over a BAT:}

1. Nonadhesive

2. Antimicrobial

3. Ability to absorb exudate

4. Maintains moisture on the BAT and within the wound site

5. Non-cytotoxic

6. Cost-effective

Of the myriad of different dressing options available that meet some of the criteria mentioned above, the AmeriGel ${ }^{\circledR}$ Hydrogel Saturated Gauze Dressing is an excellent option that meets most if not all of the characteristics above.

\section{Case Example using the BRAIN Principal}

A 47 year-old diabetic patient with profound peripheral neuropathy developed a blister on the plantar aspect of her right heel that became recalcitrant to conservative treatment. The patient's wound was debrided weekly and had Promogran $^{\text {TM }}$ (Johnson \& Johnson Wound Management, Somerville, NJ) applied to the site until the wound developed a healthy granular base. Apligraf ${ }^{\mathbb{R}}$ was chosen to close the wound, secured in place by Steri-Strips ${ }^{\mathrm{TM}}$. AmeriGel ${ }^{\mathbb{B}}$ Hydrogel Saturated Gauze Dressing covered the BAT to provide an antimicrobial barrier. A dry sterile secondary dressing was then applied. The bioburden of the BRAIN principle had been accomplished. (Fig. 1)

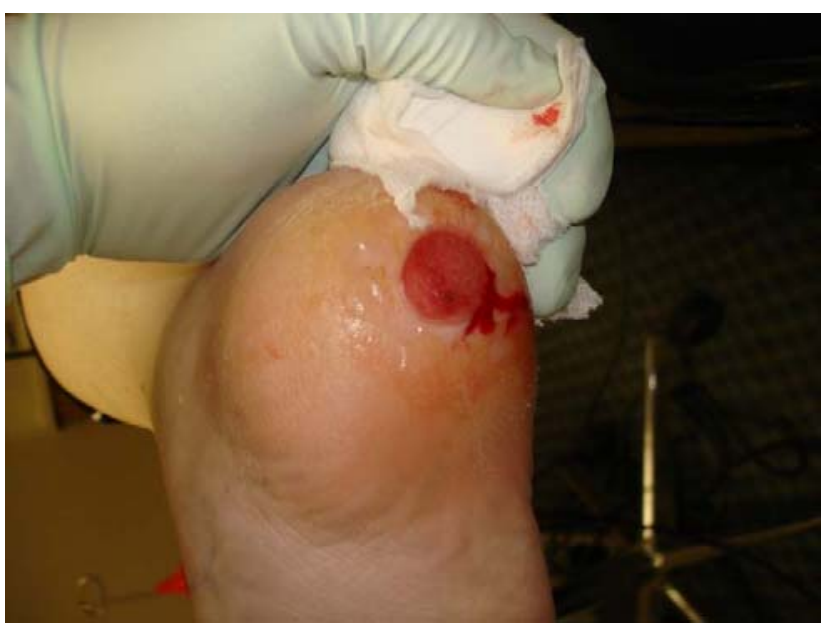

Figure 1 The Bioburden of the wound has been addressed with debridement and diligent local wound care.

To achieve the reduction of pressure and shear force, a Bledsoe ${ }^{\circledR}$ boot was utilized along with a wheel chair. Due to the patient's severe neuropathy, as well as other balance concerns, the patient could not use crutches. The primary and secondary dressings remained dry and intact for one week. (Fig. 2)

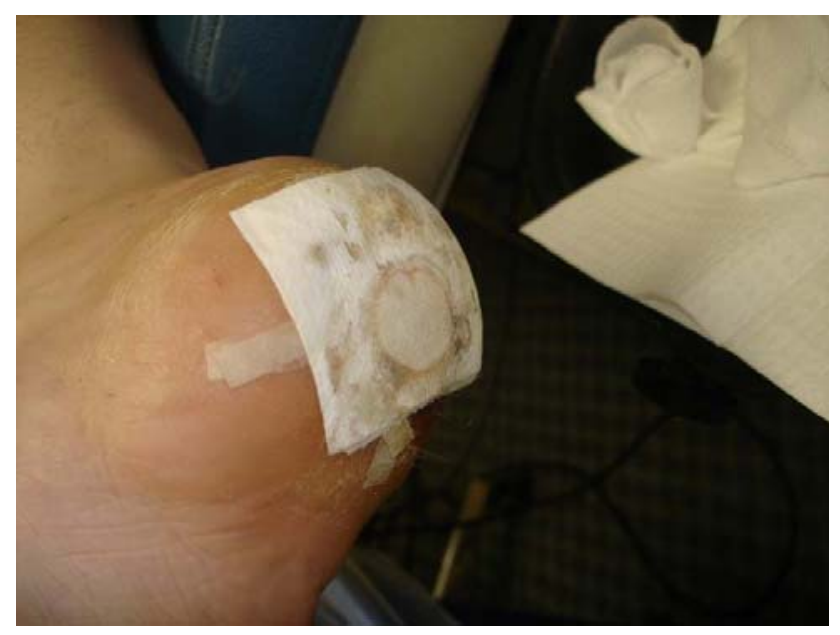

Figure 2 Reduction of pressure and shear force is essential for incorporation of the BAT.

Once the AmeriGel ${ }^{\circledR}$ Hydrogel Saturated Gauze Dressing was removed, the absorptive capability was evident as well as its ability to maintain a moist wound environment. (Fig. 3) This demonstrates adapting to the moisture needs of the BAT and of the wound.

(C) The Foot \& Ankle Journal, 2008 


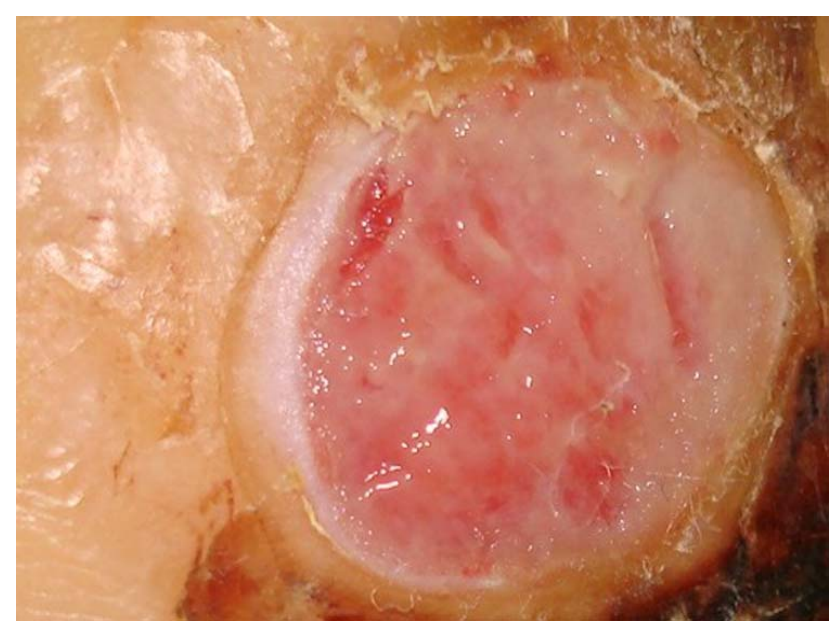

Figure 3 Adapting to the moisture needs of the wound. Here, a healthy moisture balance has been achieved using AmeriGel ${ }^{\circledR}$ Hydrogel Saturated Gauze Dressing after BAT application.

The patient returned at two weeks and Incorporation was achieved. The wound had already started to reduce in size and was considered to be a healthy granulating wound. There was no evidence of bleeding or absence of tissue caused by traumatic dressing changes. (Fig. 4)

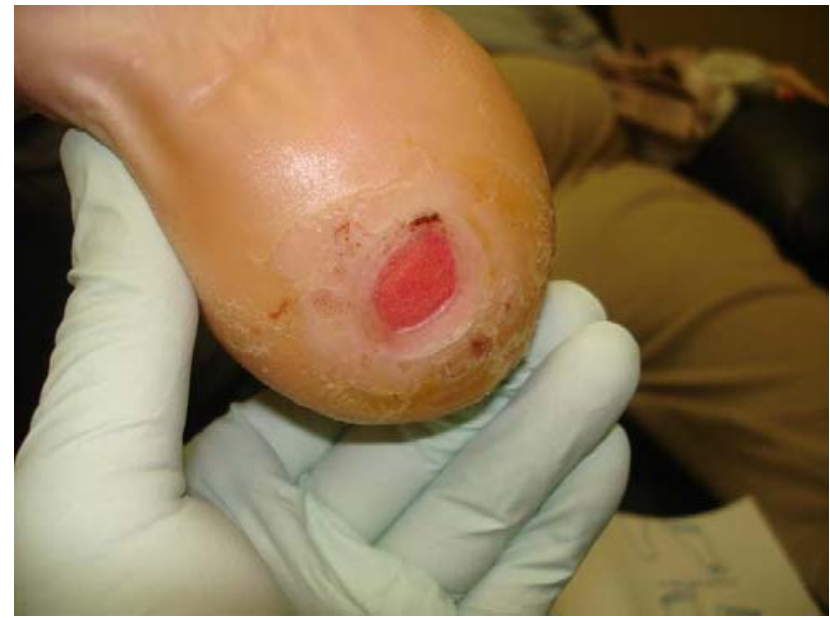

Figure 4 Incorporation of the Apligraf ${ }^{\circledR}$. Reduction of wound size is already appreciated.

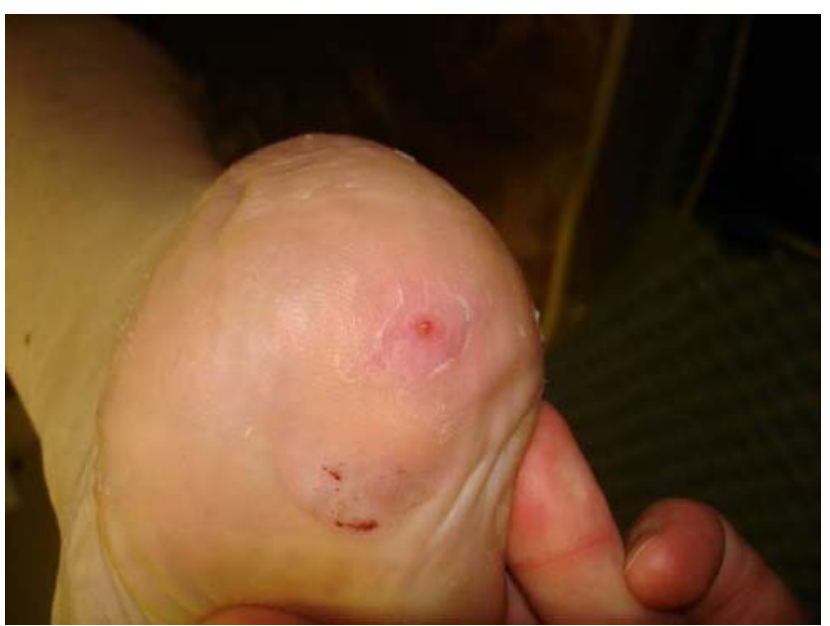

Figure 5 Nonadherence of the surrounding secondary dressings will help ensure the viability of the BAT. Using the AmeriGel ${ }^{\circledR}$ Hydrogel Saturated Gauze Dressing as a secondary dressing provides a non adherent and antimicrobial barrier to facilitate rapid wound healing.

At 4 weeks and 4 days, after daily applications of the AmeriGel ${ }^{\circledR} \quad$ Hydrogel Saturated Gauze Dressing and dry sterile gauze as the secondary dressing, the wound was healed.

The nonadherent secondary dressing played a significant role in healing this wound quickly and without the need for subsequent applications of the BAT. (Fig. 5)

\section{Conclusion}

Effective management of lower extremity ulcerations using bioengineered alternative tissues requires a multidisciplinary approach, patient involvement and the right use of the proper adjunctive tools available to the wound care specialist.

Diabetic foot ulceration is a limb and life threatening condition that requires the establishment of sound, evidence-based protocols. It is the hope of the author that protocols be established in every wound care clinic that are based upon patient outcomes, cost and ease of use for the wound care specialist and the patient. 
A protocol as described above certainly may be modified depending on many factors that may or may not be present in the wound, however the core principles as presented in the acronym BRAIN should provide a road map to maximizing the effectiveness of bioengineered tissues before, during and after BAT application.

\section{References}

1. Kim PJ, Dybowski KS, Steinberg JS. A Closer Look at Bioengineered Alternative Tissues. Podiatry Today - ISSN: 10457860 - Volume 19 - Issue 7 - Pages: 38 - 55, July 2006.

2. Pham HT, Rich J, Veves A, Using Living Skin Equivalents for Diabetic Foot Ulceration: Lower Extremity Wound 1(1);27-32, 2002.

3. Falanga V, Sabolinski M. A bilayered living skin equivalent construct (Apligraf) accelerates complete closure of hard to heal venous ulcers. Wound Repair Regen 7:201-7, 1999.

4. Bello YM, Falabella AF, Eaglstein WH. Tissue-engineered skin, current status in wound healing. Am J. Clin Dermatol 2(5):303313, 2001.

5. Claxton MJ, Armstrong DG, Boulton AJM. Healing the diabetic wound and keeping it healed: modalities for the early $21^{\text {st }}$ century. Cur Diab Rep. 2(6):510-8, Dec 2002.

6. Lee KH. Tissue-engineered human skin substitutes; development and clinical application. Yonsei Medical Journal 41(6):774-779, 2000.

7. Reiber GE: Epidemiology and health care costs of diabetic foot problems. From: The Diabetic Foot: Medical and Surgical Management, edited by Veves A, Giurini JM, LoGerfo FW, Humana Press, Totowa NJ, 2002

8. Reiber GE, Boyko EJ, Smith DG. Lower extremity foot ulcers and amputations in diabetes. In: Diabetes in America, Second Edition. Washington, DC: National Diabetes Data Group, National Institutes of Health, 409-28, 1995.

9. American Diabetes Association. Economic consequences of diabetes mellitus in the U.S.in 1997. Diabetes Care 21:296-309, 1998.

10. Sibbald RG, Williamson D, Orsted HL, Campbell K, Keast D, Krasner D, Sibbald D, Preparing the Wound Bed-Debridement, Bacterial Balance and Moisture Balance. Ostomy Wound Mgt 46: 14-35, 2000.

11. Poon, VKM, Burd A. In vitro cytoxicity of silver: Implications for clinical Wound Care. Burns 30: 140-147, 2004.

12. Edmonds, ME, Foster AM, Sanders L A. Practical Manual of Diabetic Footcare. Oxford: Blackwell Publishing, 2004.

13. Armstrong, DG, Ngugen, HC, Lavery LA, et al. Offloading the diabetic foot wound: a randomized clinical trial. Diabetes Care 24:1019-1022, 2001.

14. Winter GD: Formation of scab and rate of epithelialization of superficial wounds in the skin of the young domestic pig. Nature 193:293-294, 1962.

15. Haimowitz JE, Margolis DJ: Moist wound healing, in Krasner D, Kane D (eds): Chronic Wound Care: A Clinical Source Book for Healthcare Professionals. Wayne, PA, Health Management Publications, 49-55, 1997.
16. Geronemus RG, Robin P. The effect of two new dressings on epidermal wound healing. J Derm Surg Oncol 8:850-2, 1982.

17. Bucalo B, Eaglstein WH, Falanga V. Inhibition of cell proliferation by chronic wound fluid. Wound Rep Reg 1:181-6, 1993.

18. Coulomb B, Dubertret L. Skin cell culture and wound healing. Wound Repair Regen 10:109-12, 2002.

19. Rosales MA, Bruntz M, Armstrong DG. Gamma-irradiated human skin allograft; a potential treatment modality for lower extremity ulcers. Int. Wound J 1:201-206, 2004.

20. Shen JT, Falanga V. Innovative therapies in wound healing. J Cutan Med Surg 7(3):217-24, May-Jun 2003.

21. Eisenbud D. Huang, NF, Luke S. Silberklang M. Skin Substitutes and Wound Healing: Current Status and Challenges. Wounds 16(1): 2-17, 2004.

22. Sussman C, Bates-Jensen B. Wound healing biology and chronic wound healing. In: Wound Care- A Collaborative Practice Manual for Physical Therapists and Nurses. Gaithersburg, Md.: Aspen Publication 49-82, 1998.

23. Shultz GS, Sibbald GR, Falanga V, et al. Wound bed preparation: a systemic approach to wound management: Wound Rep Reg 11:1-28, 2003.

24. Kerstein MD. The scientific basis of healing. Adv Wound Care 10:30-6, 1997. 